\title{
Association between provincial income levels and drug prices in China over the period 2010-2017
}

\author{
Wunan Shi ${ }^{\mathrm{a}, \mathrm{b}}$, Olivier J. Wouters ${ }^{\mathrm{b}}$, Gordon Liu ${ }^{\mathrm{c}}$, Elias Mossialos ${ }^{\mathrm{b}}$, Xiuyun Yang ${ }^{\mathrm{a}, *}$ \\ a School of Economics and Finance, Xi' an Jiaotong University, Xi'an, China (Address: 74 \\ Yanta West Road, Xi'an, China, postcode: 710061) \\ ${ }^{b}$ Department of Health Policy, London School of Economics and Political Science, \\ London, U.K. (Address: Houghton Street, London, UK, postcode: WC2A 2AE) \\ ${ }^{\mathrm{c}}$ National School of Development, Peking University, Beijing, China (Address: \\ 5 Yiheyuan Road, Haidian District, Beijing, China, postcode: 100871)
}

\begin{abstract}
In the past decade, the Chinese central government has made sweeping reforms to national pharmaceutical policies. However, provincial authorities have retained control over most drug procurement procedures, potentially leading to cross-province differences in drug prices. The objectives of this study were to (i) examine drug price trends in 31 Chinese provinces and municipalities between 2010 and 2017; (ii) evaluate the association between provincial income levels and drug prices over this period; and (iii) compare the results for Chinese state-owned, Chinese private, and multinational pharmaceutical firms. Using publicly available data on procurement prices of the drugs manufactured by the top 30 pharmaceutical firms in China (in terms of revenues), we ran a generalized country-productdummy regression to compare drug prices across provinces over the study period. We conducted subgroup analyses to test for differences between types of firms. Between 2010
\end{abstract}


and 2017 , drug prices decreased by an average of $23 \%$ across the country. The prices of drugs sold by multinational firms dropped by $32 \%$ over this period, while the prices of drugs sold by Chinese private firms declined by $28 \%$. By contrast, the drug prices of state-owned firms went up by $11 \%$. There were statistically significant positive associations between drug prices and provincial income levels for the full sample in 2010, 2011, and 2013. There were no significant associations in other years. Several low-income provinces paid higher procurement prices than some high-income provinces for identical medicines, especially in later study years. The lack of association between income levels and prices poses equity concerns and may place a heavier cost burden on the poor. It also suggests that China's pharmaceutical policies may be failing to balance the dual aims of drug affordability and incentives for innovation.

\section{HIGHLIGHTS}

- Drug procurement prices dropped by an average of 23\% between 2010 and 2017 in China.

- Trends in prices varied between drugs sold by different types of firms.

- There was no association between prices and provincial incomes in most years.

- This may have placed a heavier cost burden on poorer provinces.

\section{KEYWORDS}

China; Drug procurement; Pharmaceutical reform; Price trends; Price differentials; Provinces; Firm types 


\section{INTRODUCTION}

In 2018, China had a population of nearly 1.4 billion and a per capita gross domestic product of around 9,800 USD. China is the world's second largest market for pharmaceutical products in terms of dollar sales after the United States, and the Chinese drug market is rapidly expanding. In 2018, AstraZeneca became the first major drug company to seek regulatory approval for a new drug in China ahead of the US or Europe.

The Chinese government is grappling with competing health and industrial priorities in the pharmaceutical sector. On the one hand, the government aims to guarantee drug affordability and availability for its large population. On the other, it strives to stimulate innovation in its domestic pharmaceutical industry to fuel economic growth (Xu et al., 2018).

In 2009, China launched a comprehensive round of health-care system reforms (Burns and Liu, 2017). As part of these reforms, the government made sweeping changes to national pharmaceutical policies in an attempt to bring down drug spending and to improve access to medicines for patients (Barber et al., 2013). The government introduced five major drug policies: (1) an essential medicines list, which was subsequently expanded in 2012 and 2018, (2) a zero mark-up drug policy which removed the retail mark-up on prescribed medicines, (3) a centralized drug procurement system, which was rolled out in all provinces in 2010, (4) the elimination of direct government control on the retail prices of most drugs, and (5) a streamlined regulatory system for medicines, with the aim of speeding up drug review and approval processes (Ding and Wu, 2017; Fang et al., 2013; He et al., 2018; Hu and Mossialos, 2016; Xu et al., 2018; Yip et al., 2019). The government also made changes to prescription drug coverage and reimbursement rates as part of its national insurance policies (Yip et al., 2019). 
The present study focuses on the reforms to China's centralized drug procurement system, which were meant to help the government achieve economies of scale and increase its bargaining power against drug firms. There is evidence that centralized procurement systems may result in lower drug prices than under free-market conditions (Wouters et al., 2017; Wouters et al., 2019). Procurement systems have important implications for drug affordability for patients and innovation incentives in the domestic pharmaceutical industry, as outlined in the next two sections.

\section{Pharmaceutical procurement system in China (2010-2017)}

This section reviews the key reforms to the drug procurement system in China between 2010 and 2017, which were rolled out in two stages (Gao and Zhang, 2018). The first stage, which took place in 2010, established centralized drug procurement systems at the provincial level. Prior to this reform, procurement was conducted at the facility level. Most provinces adopted a "two-envelope" tendering system. Under such a system, suppliers are first asked to submit documentation demonstrating they satisfy the drug quality standards mandated by the procurement authorities of different provinces. Only bids that have passed the first round can then be evaluated based on price (i.e., second envelope). The tender is usually awarded to the firm that offered the lowest price (Barber et al., 2013). This first stage of reforms appeared effective at reducing drug prices but was blamed for causing drug supply shortages. Tenders were often awarded to a single firm (which resulted in supply disruptions if the firm was unable to supply a product on time) and firms sometimes offered unsustainably low prices (which led some firms to later renege on their offers) (Hu and Mossialos, 2016).

To overcome these issues, the central government introduced a second stage of reforms in 2015, which consisted of two major changes (General Office of the State Council of China, 
2015; National Health and Family Planning Commission, 2015b). First, the central government adjusted the procurement procedures for companies selling certain types of products to reduce the risk of supply disruptions. For example, the reform relaxed the procurement requirements for companies supplying certain emergency, gynaecological, paediatric, and low-priced drugs at high risk of shortages, which could subsequently be procured directly online instead of through a competitive bidding process. Second, in order to improve the administration and management of the provincial drug procurement systems, the central government promoted transparency in procurement procedures.

Although the central government provides guidance to provincial authorities on the procurement of drugs, individual Chinese provinces administer the drug procurement procedures (Mossialos et al., 2016). The provincial jurisdictions have different quality assessment standards (Hu and Mossialos, 2016), which may result in varying numbers of firms making it past the first round of the "two-envelope" process. Moreover, authorities in individual provinces sometimes group medicines into different categories for price competition, which may lead to differences in bidding procedures and numbers of bidders for the same products (Ding et al., 2016). Some provinces also impose upper price limits on tender bids based on published prices from other provinces.

Three main types of firms participate in the Chinese drug procurement system: Chinese private, Chinese state-owned, and foreign multinational pharmaceutical firms. In 2017, Chinese private pharmaceutical firms recorded revenues of 812.5 billion yuan, while foreign and Chinese state-owned firms recorded revenues of 550.3 billion yuan and 236.4 billion yuan, respectively (National Bureau of Statistics, 2018). In the same year, around $97 \%$ of the drugs supplied by Chinese state-owned and private firms were generic products; state-owned firms have historically focused on the manufacture of medicines deemed to be of high importance to public health and products at risk of shortages due to low prices. Foreign 
multinational firms accounted for nearly all brand-name drugs sold in the country (World Health Organization, 2017). Firms selling generic and brand-name drugs are exposed to different levels of competition (Wang, 2006; Zhao and Wu, 2017).

\section{Differential pricing: Theoretical background}

Under the procurement system, different provinces in China may pay different prices for identical products. This could promote both access to medicines and pharmaceutical innovation: if drug companies were to charge higher prices for medicines in richer provinces than in poorer ones, differential pricing could, in theory, increase patient access to affordable drugs while still providing incentives for firms to innovate. Indeed, theoretical and simulation studies have outlined the advantages of differential pricing across drug markets over uniform pricing (Danzon and Towse, 2003; Dumoulin, 2001; Jack and Lanjouw, 2005; Malueg and Schwartz, 1994; Varian, 1985; Yadav, 2010).

There are several conceptual models for setting optimal, or welfare-maximizing, differential prices for medicines across markets, including value-based pricing and Ramsey pricing. The assumptions and policy implications of each model have been reviewed extensively elsewhere (Danzon, 2018; Danzon and Towse, 2003; Danzon et al., 2015b; Ramsey, 1927; Towse et al., 2015). Despite differences in their underlying assumptions, all models suggest that drug prices should be positively correlated with income levels in different markets. According to these models, income-related differential pricing would balance short-term social welfare with long-term sustainability of innovation in the industry (Danzon, 1997; Jack and Lanjouw, 2005; Schweitzer and Comanor, 2011; Vogler et al., 2018). 
Yet there are important reasons why these theoretical results may not hold (Danzon, 1997; Danzon and Towse, 2003; Kanavos and Wouters, 2014). First, if pharmaceutical parallel trade is allowed, then drug importers can buy products in low-price markets and sell them elsewhere. Second, reference pricing, a policy in which policymakers benchmark domestic drug prices against those in other jurisdictions, may be used to eliminate or reduce price differences between jurisdictions (Danzon, 1998; Kanavos and Costa-Font, 2005). Third, tendering schemes, in which buyers typically source drugs from the firms offering the lowest prices, may limit the opportunities for firms to charge different prices in different jurisdictions (Danzon, 1997).

The theoretical importance of income-related price differences - and the presence of potential barriers - has generated interest among researchers regarding the association of cross-country prices and income levels. Several studies have found a positive relationship between per capita income and drug prices. For example, using data on the prices charged by drug firms for nearly 6,500 medicines in 38 countries in 2008, Lichtenberg (2011) observed that drug prices were, on average, lower in poorer countries than in richer ones. Yet the author of that study noted that within individual countries some poorer patients were paying higher prices than richer patients (Lichtenberg, 2011). Similarly, another study found that the per capita gross domestic products of countries were positively associated with the unit prices of insulin, based on analysis of almost 12,000 drug prices in 186 countries between 1995 and 2013 (Helble and Aizawa, 2017).

Other researchers have observed a weak or nonexistent positive association between cross-country income levels and drug prices. Danzon et al. (2015a), using data from 2004 to 2008 on the ex-manufacturer prices of anti-infective, cardiovascular, human immunodeficiency virus, malaria, and tuberculosis medicines in 115 countries, found that the price elasticities of income were modest but positive across the full sample of countries; the 
elasticities were insignificant or negative when the analysis was restricted to poorer countries. They concluded that medicines, when benchmarked against income levels, were least affordable for patients in the lowest-income countries (Danzon et al., 2015a). Morel et al. (2011) found that drug prices were higher in some middle-income countries than in several high-income countries. Conversely, they also observed that prices in some middle-income countries were lower than in certain low-income countries. In an analysis of drug prices in 11 European Union member states, Petrou and Vandoros (2016) found that income levels had no consistent bearing on drug prices across countries.

Most studies to date have examined price differences between countries, but international price comparisons may mask inequitable price differences within countries. There is little evidence on drug prices differences between provinces in China, especially during the period of provincial drug procurement reforms initiated in 2010. And most existing analyses of drug prices in China have evaluated the retail prices charged by hospitals in selected Chinese provinces over short periods of time (Fang et al., 2013; Song et al., 2018; Wu et al., 2014; Zhao and $\mathrm{Wu}, 2017)$. Procurement prices are more relevant for understanding the impact of the procurement system on cross-province drug prices.

Using data on the procurement prices of medicines manufactured by the top 30 pharmaceutical firms in China (by revenues) between 2010 and 2017, the aims of this study were to (i) examine time trends in the prices of medicines in all 31 Chinese provinces and municipalities during the reforms; (ii) evaluate the association between provincial income levels and drug price levels over time; (iii) compare results between Chinese state-owned, Chinese private, and multinational pharmaceutical firms in a subgroup analysis, since the policy changes described earlier may have had different effects on the prices of drugs supplied by each type of firm. 


\section{MATERIALS AND METHODS}

\section{Data sources}

We collected data on procurement drug prices and manufacturers in 31 Chinese provinces and municipalities between 2010 and 2017 from the websites of the provincial drug procurement centres. Because price data were not published by all provincial governments each year, drug prices for all provinces in all eight study years were not available. We also searched the commercial database Yaozh for provincial procurement prices during this period to minimize the issue of potentially missing data. We acquired data on per capita disposable incomes of urban residents for every province in each year from the official website of the National Bureau of Statistics of China. All prices and incomes were reported in 2010 yuan to account for inflation.

Data were gathered for drugs manufactured by the 30 largest pharmaceutical firms in terms of revenues in China (Information Centre of the Chinese Pharmaceutical Industry, 2018). We categorized the firms into: (1) multinational firms, (2) Chinese private firms, and (3) Chinese state-owned firms (Box 1). For Chinese firms, the ownership type was established based on the nature of the entity that held ultimate control over the firm (e.g. the majority or plurality shareholder). To determine this, we needed to investigate the shareholding structure of the individual firms and, if necessary, their parent firms (Annual Reports of Listed Firms, 2020; National Enterprise Credit Information Publicity System, 2020). If the ultimate controller was the government or a government agency, the firm was categorized as state owned; if the controller was one or more individuals, the firm was categorized as private. Of the 30 firms in our sample, 28 firms could be clearly classified based on these rules. For the remaining two collective firms for which ownership was unclear 
(Qilu Pharmaceuticals and Yangtze River Pharmaceuticals), we followed the methodology outlined by Bai et al. (2003) and categorized them as non-state, i.e. private firms, given the lack of clear government shareholding in the two firms.

Drugs were classified by anatomical/pharmacological group based on the anatomical therapeutic chemical classification system (World Health Organization Collaborating Centre for Drug Statistics Methodology, 2019). Drugs belonging to more than one group were included in each group for the analyses. We excluded Chinese traditional medicines when categorizing drugs by group. Drugs belonging to the following groups were excluded from the subgroup analyses due to small sample sizes $(\mathrm{n} \leq 15)$ : systemic hormonal preparations, excluding sex hormones and insulins (group $\mathrm{H}$ ) and antiparasitic products, insecticides and repellents (group P).

To ensure the accuracy of our analysis, we restricted the price comparisons to drugs with the same generic name, form, strength, pack size, and manufacturer. We matched drugs based on these characteristics across provinces and years. If a drug was procured in a single year and in a single province, it was excluded from our analysis because it did not aid with comparisons.

\section{Statistical analysis}

As procurement was conducted at the provincial level, individual provinces had different mixes of drugs in their samples, meaning the price data for comparison was incomplete. Incomplete data is commonly encountered in international price comparisons of goods and services across jurisdictions. The country-product-dummy method is a hedonic regression model used to calculate spatial price indices and purchasing power parities in international price comparisons (Diewert, 2010; Rao, 2004; Summers, 1973). It addresses difficulties in 
comparing the prices of different commodity mixes across jurisdictions. For our analysis, it is a suitable method as long as any two of the provinces can be directly or indirectly connected by one or more drugs (Diewert, 2010).

We generalized the country-product-dummy method for comparing drug price levels across different provinces and over time, with the basic model expressed as

$$
p_{n c t}=a_{c t} b_{n} u_{n c t}, \quad n=1,2 \ldots, N, \quad c=1,2, \ldots, C, \quad t=1,2, \ldots, T,
$$

where $p_{n c t}$ is the price of $\operatorname{drug} n$ in province $c$ and year $t, a_{c t}$ is a province and year dependent variable, $b_{n}$ is a drug dependent variable, and $u_{n c t}$ is the error term. In this way, the country-product-dummy method decomposes variations in drug prices into differences across provinces and time $\left(a_{c t}\right)$ and differences across drugs $\left(b_{n}\right)$. The variable $a_{c t}$ is assumed to be independent of $n$ and thus suitable for our price comparison across provinces and years. In this paper, $a_{c t}$ is referred to as the drug price index in province $c$ and year $t$.

Taking the logarithm of (1) we obtain the following linear model

$$
y_{n c t}=\alpha_{c t}+\gamma_{n}+v_{n c t}, \quad n=1,2 \ldots, N, \quad c=1,2, \ldots, C, \quad t=1,2, \ldots, T,
$$

where $y_{n c t}=\log \left(p_{n c t}\right), \alpha_{c t}=\log \left(a_{c t}\right), \gamma_{n}=\log \left(b_{n}\right)$, and $v_{n c t}=\log \left(u_{n c t}\right)$. To estimate the parameters $\alpha_{c t}$ and $\gamma_{n}$, we can rewrite the $k$-th observed price using two sets of dummy variables in the following form

$$
y_{k}=\sum_{c=1}^{C} \sum_{t=1}^{T} \alpha_{c t} D_{k c t}+\sum_{n=1}^{N} \gamma_{n} D_{k n}^{*}+v_{k}, \quad k=1,2, \ldots, K
$$


where $D_{k c t}$ is the joint province and year dummy variable which equals one if the $k$-th price is associated with province $c$ and year $t$, and zero otherwise, $D_{k n}^{*}$ is the product dummy variable which equals one if the price is associated with drug $n$ and zero otherwise, and $K$ is the total number of price observations. After imposing a linear restriction on the parameters, i.e., $\alpha_{11}=0$, meaning that the first province in the first study year is chosen as the base in the price comparisons, model (3) is estimated using ordinary least squares. The drug price indices can then be obtained as $\hat{a}_{c t}=\exp \left(\hat{\alpha}_{c t}\right)$. For the subgroup analyses by firm type and anatomical/pharmacological group, the regression in model (3) was conducted separately for each subgroup. It is worth noting that because the joint province and year dummy variable captured price variations across provinces and years, separate province and year dummy variables were not included in model (3). Additional dummy variables would have resulted in exact collinearity.

When the price data is complete, each $\widehat{\alpha}_{c t}$ estimated from model (3) has the closed-form expression $\hat{\alpha}_{c t}=\frac{1}{N} \sum_{n=1}^{N}\left(y_{n c t}-y_{n 11}\right)$, i.e., the price index is obtained by directly comparing prices between $c t$ and the base. When the price data is incomplete, indirect comparisons such as $\left(y_{n_{1} c t}-y_{n_{1} c^{\prime} t^{\prime}}\right)$ and $\left(y_{n_{2} c^{\prime} t^{\prime}}-y_{n_{2} 11}\right)$ also contribute to $\hat{\alpha}_{c t}($ Rao, 2004). The price index is the integrated outcome of all within-drug price differences, and therefore unaffected by the absolute prices of the studied drugs.

It is also important to note that the statistical significance of an estimated $\widehat{\alpha}_{c t}$ should not be viewed as having the same implication as in the slope coefficient estimation. The countryproduct-dummy method can be thought of as the intercept estimation, where the significance largely depends on the choice of the base. Even if estimates were insignificant, they still show how the price levels differed from that of the base. Therefore, the statistical significance of each $\hat{\alpha}_{c t}$ was not reported in our analysis. In addition, although the price variations across drugs $\hat{b}_{n}=\exp \left(\hat{\gamma}_{n}\right)$ were also obtained from model (3), they were irrelevant in our price 
comparison and were thus not reported. The data were analysed in MATLAB 2012 (MathWorks Inc., Massachusetts, USA).

\section{RESULTS}

\section{Summary statistics}

In total, 47,377 prices of 2,766 drugs in 31 provinces were available between 2010 and 2017. This included 28,360 drug prices for 1,365 drugs sold by 18 Chinese private firms; 6,837 drug prices for 256 drugs sold by 6 multinational firms; and 12,180 prices for 1,145 drugs sold by 6 Chinese state-owned firms. The product characteristics (i.e. anatomical/pharmacological group and generic status) by firm type are summarized in the Appendix.

Figure 1 shows the empirical cumulative distribution functions of the procurement prices of drugs manufactured by Chinese private firms, Chinese state-owned firms, and multinational firms. The figure shows that drugs sold by multinational firms were generally more expensive than those sold by Chinese firms (private or state owned). State-owned firms accounted for the largest share of low-priced drugs in the sample. Roughly $90 \%$ of drugs sold by state-owned firms and about $80 \%$ of drugs sold by Chinese private firms were priced below 55 yuan $(\approx \exp (4))$, while only about $30 \%$ of drugs from multinational firms were priced below this amount. The price distributions for drugs with the same generic name sold by one, two, or three types of firms are shown in the Appendix. Although the price distributions for multinational firms were comparable in each case, the cumulative distribution functions of prices of products sold by Chinese private firms and state-owned 
firms appeared more similar when there were two and three types of firms supplying a particular product.

\section{Price differences between provinces}

Table 1 shows the estimated drug price indices for the 31 Chinese provinces between 2010 and 2017 for the full sample. The provinces were ranked based on per capita income of urban residents (in 2014). The price index of Beijing in 2010 was used as the reference in the analysis.

The drug procurement price indices varied greatly between provinces. In many of the study years, drug prices were roughly two times as expensive in the provinces with the highest prices as in the provinces with the lowest prices. However, when visually inspecting the price indices, there was no clear pattern across provinces with different income levels. For example, in 2017, drug price levels in Shanghai and Beijing, the two regions with the highest per capita income levels, were just above the national average. Jiangsu and Guangdong, two of the six regions with the highest income levels, had drug price levels below the country average in most of the study years. In 2014, even though the per capita income in Beijing was about two times higher than in Gansu, Guizhou, and Yunnan, Beijing had a lower price index than these three poorer western provinces. In some cases, poorer provinces, such as Shaanxi and Xinjiang, had lower drug price levels than some of the richer provinces.

The price indices for all provinces and years in the subgroup analyses of Chinese private firms, state-owned firms, and multinational firms are presented in Appendix; there was no clear association between price indices and provincial income levels when the results were broken down by firm type. 


\section{Price trends}

Figure 2 shows the variation in the price indices (average across all 31 provinces) between 2010 and 2017 for the full sample and for each type of firm. Overall, drug prices fell by an average of $23 \%$ in China over the study period, although there was a spike in prices in 2015. The biggest year-on-year drops in prices were observed in 2010-2011 and 2015-2016, when new stages of the reforms to the procurement procedures were introduced. Price trends differed across provinces (Table 1). For example, Zhejiang, one of the richest provinces, achieved a reduction of about $50 \%$ in its drug procurement price over the study period. Price trends differed across firm types (Figure 2). The prices of drugs sold by multinational firms decreased steadily by $32 \%$ over the study period. The prices charged by Chinese private firms experienced a sharp decline after the reform in 2010 before levelling off, with a reduction of $28 \%$ over the whole period. The drug prices of state-owned firms went up $11 \%$ over the study period, with a jump in prices in 2015 .

Figure 3 presents the price trends (average across all 31 provinces) by different anatomical/pharmacological groups. The prices of drugs in groups L (antineoplastic and immunomodulating agents) and V (various) fell consistently over time, exhibiting the largest decline over the study period. For example, the prices of drugs in group V dropped by approximately $50 \%$ between 2010 and 2017 . The prices of drugs in other groups also decreased over the study period, although upticks in prices were observed in some years. For instance, the prices of drugs in groups B (blood and blood forming agents) and C (cardiovascular system) fell by about $10 \%$ over the eight years.

\section{Association between drug prices and income levels}


Figure 4 presents the association between drug price indices and provincial income levels of the 31 provinces from 2010 to 2017. The regression of drug price indices on provincial incomes for each year was represented by a trend line in the figure, where the coefficients of provincial incomes are indicated. The same regression was conducted in the subgroup analyses to investigate the association for different types of firms (Appendix).

In the full sample of firms (Figure 4), there were significant positive associations in 2010, 2011, and 2013, but there were no significant correlations in other years. The subgroup analysis of Chinese private firms showed a similar pattern to that observed in the full sample. Apart from the significant positive relationship for multinational firms in 2013, the subgroup analyses of state-owned firms and multinational firms revealed no statistically significant associations between drug price levels in Chinese provinces and income levels (Appendix). In Figure 5, the association is shown as the average over the eight study years for drugs sold by different types of firms. Drug price levels remained largely constant as income levels increased in both the full and the subgroup analyses of all three types of firms.

As a robustness check, the 31 provinces were grouped into three income-level categories (high [10 provinces], middle [11 provinces], and low [10 provinces]) to evaluate whether there was any association between these categories and price indices (Appendix). In 2010 and 2011, the price index was largest for the high-income category (i.e., the 10 richest provinces) and it was the smallest for the low-income category (i.e., the 10 poorest provinces). No consistent pattern was observed in later years. For instance, in 2014, the price index for the middle-income category was the highest. In the last two years, the price index for the high-income category was the lowest. Like in the main analysis, the price comparison between provincial categories shows a positive relationship between prices and income levels in some of the early years which disappeared in subsequent years. 


\section{DISCUSSION}

Procurement prices for the drugs included in this study declined between 2010 and 2017, during a period of reform to the centralized drug procurement. This is consistent with the results reported in earlier studies (Barber et al., 2013; Fang et al., 2013). The results in the present study held for drugs in all therapeutic areas.

Price trends varied for products sold by different types of firms. Multinational firms experienced larger price decreases over the study period than did either Chinese state-owned or private firms. This might be explained by the fact that, in recent years, the Chinese government has introduced policies aimed at putting downward pressure on the high prices of brand-name drugs, which are mostly supplied by larger multinational firms. For example, since 2015, the Chinese national government aggregated the demand for several pilot drugs covered by the national public health insurance scheme to increase its bargaining power in national price negotiations with multinational firms (National Health and Family Planning Commission, 2015a). The analysis also showed that the introduction of centralized procurement achieved considerable price reduction for drugs produced by Chinese private firms, especially immediately after reforms were introduced in 2010 and 2015 . One possible explanation is that following the reforms, the new procedures of tendering suddenly intensified competition between firms selling generic drugs by grouping bidders differently.

In contrast, the procurement prices of drugs sold by state-owned firms increased slightly over the study period. This might be explained by the fact that the national government relaxed price controls for critical and low-priced emergency drugs, which are more likely to be supplied by state-owned firms than the other two types of firms. In 2014, the central government abolished the retail price ceiling policy for low-priced drugs, before extending the policy to most drugs the next year (National Development and Reform Commission, 
2014, 2015). In 2015, the government also started allowing firms selling low-priced products to participate in direct online procurement for these drugs, in an attempt to improve supply security. This might explain the uptick in the prices of drugs sold by state-owned firms observed in 2015, after these changes had come into effect.

This paper sought to examine whether drug procurement prices were associated with income levels across Chinese provinces between 2010 and 2017. Significant positive relationships were observed in some of the early study years for the full sample, but in none of the later years. This pattern was particularly pronounced for drugs sold by Chinese private firms: drugs from Chinese private firms had positive price differentials, relative to provincial incomes, at the beginning of the study period, but this association did not persist.

Multinational firms and state-owned firms generally did not show any consistent incomerelated variation. This is of interest because differential pricing has the potential to balance the current need for drug affordability and future welfare through the emergence of researchbased local drug industry in China. Indeed, in more recent years, some middle- and lowincome provinces had higher procurement prices than high-income provinces, potentially leading to heavier cost burdens for the poor.

The lack of association between provincial income levels and drug prices could also harm the development of the domestic pharmaceutical industry. The possible revenue shortfall compared to revenues that could be made under differential pricing may discourage the research and development investment into new drug discovery. This may lead to problems for the domestic economy since China has opened its pharmaceutical market to innovative drugs sold by multinational firms, meaning domestic pharmaceutical firms must engage with global competitors under the same regulatory requirements (Xu et al., 2018).

Public hospitals and other health-care facilities in individual provinces are prohibited from purchasing drugs from other provinces. However, many provincial government agencies 
use inter-provincial reference pricing to prevent firms from offering excessive prices. For instance, in 2017, Zhejiang, one of the richer provinces, requested manufacturers to disclose the prices for their products in other provinces, and the province set its initial procurement price as the lowest price found anywhere in the country (The Medicines and Medical Devices Procurement Centre in Zhejiang province, 2017). Provinces set their baseline procurement prices using different price references, often the lowest price in selected regions or in the whole country. This was made easier after the 2015 pharmaceutical reform which promoted price transparency. This policy change might help explain why positive income-related differentials for drug prices were observed in some early study years, but not in the later ones.

This study had limitations. First, data on some drug prices were missing since some provincial authorities did not publish all data in certain years; it is unclear in which direction the missing data may have skewed the results, if at all. Second, drug prices are not the only factors influencing drug availability and affordability. It is also important to consider the breadth and depth of insurance coverage, as well as the types and volumes of products procured in individual provinces and whether these match the health needs of different populations. Third, procurement prices were assumed to be a reasonable proxy for both exmanufacturer prices (indicator of incentives for innovation) and retail prices (indicator of drug affordability), but this assumption might not have held in all cases. The difference between procurement prices and ex-manufacturer prices is the cost of logistics and distribution, which could differ, as a proportion of procurement prices, across provinces. Meanwhile, procurement and retail prices might have differed due to the heterogenous implementation of the zero mark-up policy. In addition, large hospitals, which are often located in richer provinces, could negotiate further discounts on bulk orders ( $\mathrm{Hu}$ and Mossialos, 2016). This could exacerbate inequities across provinces. Fourth, our study on drug procurement prices did not consider income disparity within a province. Provincial 
income-related procurement prices could lead to financial hardship for poorer patients in richer provinces. It is important for policymakers to evaluate coverage plans offered by different insurance schemes in each province, and to coordinate pharmaceutical procurement policies with insurance plans as part of the ongoing health system reforms in China.

\section{CONCLUSION}

In the past decade, the Chinese government has made sweeping reforms to its drug procurement system and has achieved a sizable reduction in drug prices. However, little attention has been placed on drug price differentials across provinces. This study used drug prices from the top 30 pharmaceutical firms in China to investigate whether drug procurement prices of these firms varied positively with incomes between 2010 and 2017, a period spanning two major drug procurement reforms in China. In general, no correlation between drug prices and provincial per capita incomes was observed within China, which raises major concerns about inequity and could be economically inefficient. As the government proceeds with pharmaceutical policy reforms, it should monitor income-related price differences to examine whether they are aligned with national drug policy objectives. 


\section{REFERENCES}

Annual Reports of Listed Firms, 2020. Retrieved from http://www.cninfo.com.cn/new/index, accessed date: 26 April, 2020.

Bai, C.E., Li, D.D., Wang, Y., 2003. Thriving on a tilted playing field. In N. Hope, D. Yang, M. Li (Eds.), How Far Across the Rivers? Chinese Policy Reform at the Millennium (pp. 97121). California: Stanford University Press.

Barber, S.L., Huang, B., Santoso, B., Laing, R., Paris, V., Wu, C., 2013. The reform of the essential medicines system in China: a comprehensive approach to universal coverage. Journal of Global Health. 3, 1-9. https://doi.org/10.7189/jogh.03.010303

Burns, L.R., Liu, G.G. (Eds.), 2017. China's healthcare system and reform. Cambridge: Cambridge University Press.

Danzon, P.M., 1997. Price discrimination for pharmaceuticals: welfare effects in the US and the EU. International Journal of the Economics of Business. 4, 301-322.

https://doi.org/10.1080/758523212

Danzon, P. M., 1998. The economics of parallel trade. Pharmacoeconomics. 13, 293-304. https://doi.org/10.2165/00019053-199813030-00004 
Danzon, P.M., 2018. Differential pricing of pharmaceuticals: theory, evidence and emerging issues. PharmacoEconomics. 36, 1395-1405. https://doi.org/10.1007/s40273-018-0696-4 https://doi.org/10.1007/s40273-018-0696-4

Danzon, P.M., Mulcahy, A.W., Towse, A.K., 2015a. Pharmaceutical pricing in emerging markets: effects of income, competition, and procurement. Health Economics. 24, 238-252. https://doi.org/10.1002/hec.3013

Danzon, P. M., Towse, A.K., 2003. Differential pricing for pharmaceuticals: reconciling access, R\&D and patents. International Journal of Health Care Finance and Economics. 3, 183-205. https://doi.org/10.2139/ssrn.422821

Danzon, P.M., Towse, A.K., Mestre-Ferrandiz, J., 2015b. Value-based differential pricing: efficient prices for drugs in a global context. Health Economics. 24, 294-301. https://doi.org/10.1002/hec.3021

Diewert, E., 2010. New methodological developments for the International Comparison Program. Review of Income and Wealth. 56, 11-31. https://doi.org/10.1111/j.14754991.2010.00398.x

Ding, J., Dong, R., Wei, L.I., Gong, B., Wang, J., 2016. Assessment and rational thinking of "Bidding Group" in Chinese centralized drug procurement system. Chinese Journal of Health Policy. 9, 52-59. https://doi.org/10.3969/j.issn.1674-2982.2016.09.010 
Ding, L., Wu, J., 2017. The impact of China's National Essential Medicine Policy and its implications for urban outpatients: a multivariate difference-in-differences study. Value in Health. 20, 412-419. https://doi.org/10.1016/j.jval.2016.10.018

Dumoulin, J., 2001. Global pricing strategies for innovative essential drugs. International Journal of Biotechnology. 3, 338-349. https://doi.org/10.1504/IJBT.2001.000169

Fang, Y., Wagner, A.K., Yang, S., Jiang, M., Zhang, F., Ross-Degnan, D., 2013. Access to affordable medicines after health reform: evidence from two cross-sectional surveys in Shaanxi Province, western China. The Lancet Global Health. 1, e227-e237. https://doi.org/10.1016/S2214-109X(13)70072-X

Gao, H., Zhang, A., 2018. Retrospective and prospective on the medicine procurement system. China Social Security. 289: 82-83.

General Office of the State Council of China, 2015. The guideline on improving the centralized drug procurement system for public hospitals. http://www.gov.cn/zhengce/content/2015-02/28/content_9502.htm, accessed date: 9 September 2019.

He, Y., Dou, G., Huang, Q., Zhang, X., Ye, Y., Qian, M., Ying, X., 2018. Does the leading pharmaceutical reform in China really solve the issue of overly expensive healthcare services? Evidence from an empirical study. PloS One. 13, e0190320. https://doi.org/10.1371/journal.pone.0190320 
Helble, M., Aizawa, T., 2017. International trade and determinants of price differentials of insulin medicine. Health Policy and Planning. 32, 1-10. https://doi.org/10.2139/ssrn.2703675

Hu, J., Mossialos, E., 2016. Pharmaceutical pricing and reimbursement in China: when the whole is less than the sum of its parts. Health policy. 120, 519-534.

https://doi.org/10.1016/j.healthpol.2016.03.014

Information Centre of the Chinese Pharmaceutical Industry, 2018. The $35^{\text {th }}$ national annual meeting for the information on the Chinese pharmaceutical industry. Retrieved from https://www.sohu.com/a/245287517_502689, accessed date: 10 May, 2020.

Jack, W., Lanjouw, J.O., 2005. Financing pharmaceutical innovation: How much should poor countries contribute? The World Bank Economic Review. 19, 45-67. https://doi.org/10.1093/wber/lhi005

Kanavos, P., Costa-Font, J., 2005. Pharmaceutical parallel trade in Europe: stakeholder and competition effects. Economic Policy. 20, 758-798. https://doi.org/10.1111/j.14680327.2005.00150.x

Kanavos, P., Wouters, O.J., 2014. Pharmaceutical parallel trade: legal, policy, and economic issues. Encyclopaedia of Health Economics. 20-28. https://doi.org/10.1016/B978-0-12$375678-7.01213-\mathrm{X}$ 
Lichtenberg, F.R., 2011. Pharmaceutical companies' variation of drug prices within and among countries can improve long-term social well-being. Health Affairs. 30, 1539-1544. https://doi.org/10.1377/hlthaff.2010.0891

Malueg, D.A., Schwartz, M., 1994. Parallel imports, demand dispersion, and international price discrimination. Journal of International Economics. 37, 167-195. https://doi.org/10.1016/0022-1996(94)90044-2

Morel, C.M., McGuire, A., Mossialos, E., 2011. The level of income appears to have no consistent bearing on pharmaceutical prices across countries. Health Affairs. 30, 1545-1552. https://doi.org/10.1377/hlthaff.2010.0317

Mossialos, E., Ge, Y., Hu, J., Wang, L., 2016. Pharmaceutical policy in China: challenges and opportunities for reform. Copenhagen: World Health Organization. Regional Office for Europe.

National Bureau of Statistics, 2018. Retrieved from http://data.stats.gov.cn/easyquery.htm?cn=C01\&zb=A0N0T03\&sj=2018, accessed date: 1 May, 2020.

National Development and Reform Commission, 2014. The notification on improving price management for low-priced drugs. http://www.gov.cn/xinwen/201405/08/content_2674857.htm, accessed date: 8 May 2020. 
National Development and Reform Commission, 2015. The notification on promoting the price reform of medicines. http://www.ndrc.gov.cn/gzdt/201505/t20150505_690676.html, accessed date: 9 September 2019.

National Enterprise Credit Information Publicity System, 2020. Retrieved from http://www.gsxt.gov.cn/index.html, accessed date: 26 April, 2020.

National Health and Family Planning Commission, 2015a. The annoucement of national negotiation in centralized drug procurement. http://www.nhc.gov.cn/, accessed date: 9 September 2019.

National Health and Family Planning Commission, 2015b. The guideline on improving the centralized drug procurement system for public hospitals. http://www.nhc.gov.cn/, accessed date: 9 September 2019.

Petrou, P., Vandoros, S., 2016. Pharmaceutical price comparisons across the European Union and relative affordability in Cyprus. Health Policy and Technology. 5, 350-356. https://doi.org/10.1016/j.hlpt.2016.07.009

Ramsey, F.P., 1927. A contribution to the theory of taxation. The Economic Journal. 37, 4761.

Rao, D.S.P., 2004. The country-product-dummy method: a stochastic approach to the computation of purchasing power parities in the ICP. In SSHRC Conference on Index Numbers and Productivity Measurement (Vol. 30). 
Schweitzer, S.O., Comanor, W.S., 2011. Prices of pharmaceuticals in poor countries are much lower than in wealthy countries. Health affairs. 308, 1553-1561. https://doi.org/10.1377/hlthaff.2009.0923

Song, Y., Bian, Y., Zhen, T., 2018. Making medicines more accessible in China: an empirical study investigating the early progress of essential medicine system. PloS One. 13: e0201582. https://doi.org/10.1371/journal.pone.0201582

Summers, R., 1973. International price comparisons based upon incomplete data. Review of Income and Wealth. 19, 1-16. https://doi.org/10.1111/j.1475-4991.1973.tb00870.x

The Medicines and Medical Devices Procurement Centre in Zhejiang province, 2017. Notification on implementing the national lowest price for the online purchase. https://www.cn-healthcare.com/article/20170223/content-489865.html, accessed date: 9 September 2019.

Towse, A., Pistollato, M., Mestre-Ferrandiz, J., Khan, Z., Kaura, S., Garrison, L., 2015. European Union pharmaceutical markets: a case for differential pricing? International Journal of the Economics of Business. 22, 263-275. https://doi.org/10.1080/13571516.2015.1045747

Varian, H.R., 1985. Price discrimination and social welfare. American Economic Review. 75, 870-875. https://doi.org/10.1016/0309-586X(85)90093-7 
Vogler, S., Paris, V., Panteli, D., 2018. Ensuring access to medicines: how to redesign pricing, reimbursement and procurement? World Health Organization Technical Report. Report number: Policy Brief No. 29.

Wang, Y. R., 2006. Price competition in the Chinese pharmaceutical market. International Journal of Health Care Finance and Economics. 6, 119-129. https://doi.org/10.1007/s10754006-5558-5.

WHO Collaborating Centre for Drug Statistics Methodology, 2019. Guidelines for ATC classification and DDD assignment 2020. Oslo, Norway.

World Health Organization, 2017. China policies to promote local production of pharmaceutical products and protect public health. Geneva. Licence: CC BY-NCSA 3.0 IGO.

Wouters, O.J., Kanavos, P.G., McKee, M., 2017. Comparing generic drug markets in Europe and the United States: prices, volumes, and spending. The Milbank Quarterly. 95, 554-601. https://doi.org/10.1111/1468-0009.12279

Wouters, O.J., Sandberg, D.M., Pillay, A., Kanavos, P.G., 2019. The impact of pharmaceutical tendering on prices and market concentration in South Africa over a 14-year period. Social Science \& Medicine. 220, 362-370.

https://doi.org/10.1016/j.socscimed.2018.11.029 
Wu, J., Xu, J., Liu, G., Wu, J., 2014. Pharmaceutical pricing: an empirical study of market competition in Chinese hospitals. PharmacoEconomics. 32, 293-303.

https://doi.org/10.1007/s40273-013-0099-5

Xu, L., Gao, H., Kaitin, K.I., Shao, L., 2018. Reforming China's drug regulatory system. Nature Reviews Drug Discovery. 17, 858-859. https://doi.org/10.1038/nrd.2018.150

Yadav, P., 2010. Differential pricing for pharmaceuticals: review of current knowledge, new findings and ideas for action. Great Britain, Department for International Development. Retrieved from http://www.dfid.gov.uk/Documents/publications1/prd/diff-pcing-pharma.pdf

Yip, W., Fu, H., Chen, A.T., Zhai, T., Jian, W., Xu, R., ..., Mao, W., 2019. 10 years of healthcare reform in China: progress and gaps in Universal Health Coverage. The Lancet. 394, 1192-1204. http://doi.org/10.1016/S0140-6736(19)32136-1

Zhao, M., Wu, J., 2017. Impacts of regulated competition on pricing in Chinese pharmaceutical market under urban employee basic medical insurance. Expert Review of PharmacoEconomics \& Outcomes Research. 17, 311-320.

https://doi.org/10.1080/14737167.2017.1251318. 
Box 1. List of top 30 pharmaceutical firms (in terms of revenues in China) by ownership category.

\section{Multinational Firms}

1. AstraZeneca

2. Bayer

3. Novo Nordisk

4. Pfizer

5. Roche

6. Sanofi

\section{Chinese Private Firms}

1. Chia Tai Tianqing Pharmaceuticals

2. China Grand Enterprises

3. China Shijiazhuang Pharmaceuticals

4. Huadong Medicine

5. Humanwell Group

6. Jemincare

7. Jiangsu Hansoh Pharmaceuticals

8. Jiangsu Hengrui Medicine

9. Livzon Pharmaceuticals

10. Lunan Pharmaceuticals

11. Qilu Pharmaceuticals

12. Shandong Buchang Pharmaceuticals

13. Shanghai Fosun Pharmaceuticals

14. Sichuan Kelun Pharmaceuticals 
15. The United Laboratories

16. Wego

17. Xiuzheng Pharmaceuticals

18. Yangtze River Pharmaceuticals

\section{Chinese State-Owned Firms}

1. Beijing Tongrentang Chinese Medicine

2. China National Pharmaceutical Group

3. China Resources Pharmaceutical Group

4. Guangzhou Pharmaceuticals

5. Shanghai Pharmaceuticals

6. Tianjin Pharmaceuticals

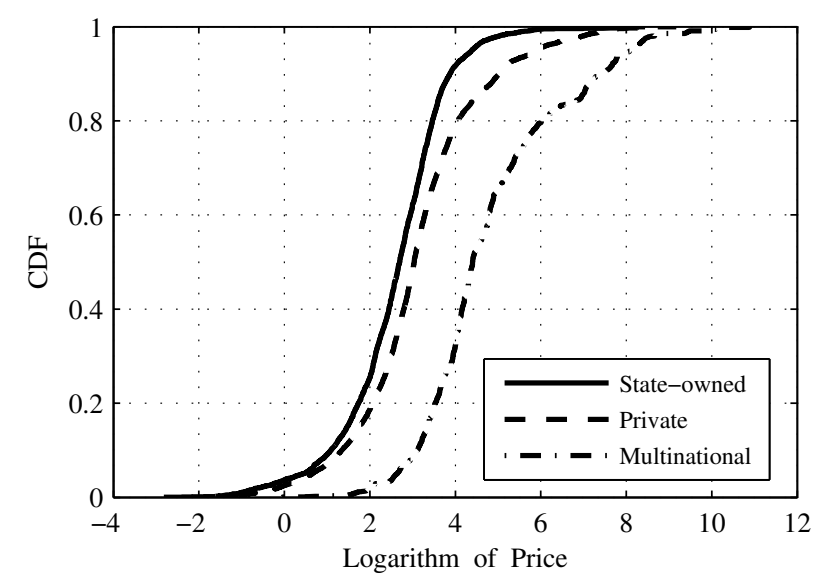

Figure 1. The empirical cumulative distribution functions of the drug procurement prices (in yuan) for Chinese private firms, Chinese state-owned firms, and multinational firms.

Table 1. Estimated drug price indices for 31 provinces and 8 years for the full sample, with Beijing (2010) as the base. 


\begin{tabular}{|c|c|c|c|c|c|c|c|c|}
\hline Province & 2010 & 2011 & 2012 & 2013 & 2014 & 2015 & 2016 & 2017 \\
\hline Shanghai & 0.98 & 1.16 & - & 1.1 & 0.86 & 0.92 & 0.81 & 0.73 \\
\hline Beijing & 1 & - & - & 0.82 & 0.74 & 0.72 & 0.69 & 0.75 \\
\hline Zhejiang & 1.04 & 0.72 & - & 0.86 & 0.96 & 0.71 & 0.83 & 0.51 \\
\hline Jiangsu & 1 & 0.72 & 0.65 & 0.79 & 0.75 & 0.85 & 0.75 & 0.61 \\
\hline Guangdong & - & 0.85 & 0.73 & 0.78 & 0.58 & 0.69 & 0.69 & 0.63 \\
\hline Tianjin & 0.99 & - & 0.62 & 0.91 & - & 0.99 & 0.67 & 0.52 \\
\hline Fujian & 0.71 & - & 0.76 & - & - & 0.75 & 0.64 & 0.74 \\
\hline Shandong & - & 0.94 & 1.03 & 0.74 & 0.74 & 0.91 & 0.66 & 0.65 \\
\hline Liaoning & 1.01 & 0.66 & - & 0.96 & - & - & 0.72 & 0.77 \\
\hline Inner Mongolia & 1.09 & 0.96 & 0.83 & - & 1.05 & 1.23 & 0.82 & - \\
\hline Hunan & 0.99 & 0.72 & - & 0.85 & 0.79 & 0.71 & 0.75 & 0.66 \\
\hline Chongqing & - & - & - & - & - & - & - & 0.82 \\
\hline Hubei & 0.9 & 0.64 & - & 0.79 & 0.72 & 0.74 & 0.8 & 0.73 \\
\hline Anhui & 0.64 & 0.73 & 0.85 & 0.81 & 0.73 & 0.73 & - & 0.67 \\
\hline Guangxi & 1.1 & 0.92 & 0.74 & 0.71 & 0.89 & 0.84 & 0.93 & 0.86 \\
\hline Hainan & - & - & 0.56 & 0.82 & 0.83 & - & 0.92 & 0.77 \\
\hline Shaanxi & 0.72 & - & 0.8 & 0.79 & 0.75 & 0.78 & 0.69 & 0.68 \\
\hline Jiangxi & 0.92 & 0.54 & 0.88 & 0.66 & 1 & 0.67 & 0.58 & 0.94 \\
\hline Yunnan & - & 0.95 & 0.81 & 0.88 & 0.79 & 0.99 & 1.02 & 0.82 \\
\hline Sichuan & 0.95 & 0.86 & - & 0.83 & 0.95 & 0.74 & 0.9 & 0.69 \\
\hline Hebei & 0.97 & 0.86 & 0.92 & - & - & - & - & - \\
\hline Shanxi & 0.92 & 0.92 & 0.81 & 0.88 & 0.9 & 0.89 & 0.93 & 0.62 \\
\hline Henan & 0.95 & 0.84 & 0.93 & - & 0.68 & 0.8 & - & 0.75 \\
\hline Ningxia & 0.78 & 0.81 & 0.81 & 0.83 & 0.75 & 0.78 & 0.58 & 0.7 \\
\hline Jilin & 0.99 & 0.64 & - & 0.85 & 0.79 & 0.74 & 0.66 & 0.64 \\
\hline Xinjiang & 0.86 & 0.69 & 1.15 & 0.77 & 0.89 & - & - & 0.67 \\
\hline Heilongjiang & 0.83 & 0.65 & - & - & - & 0.72 & 0.79 & 0.78 \\
\hline Guizhou & 0.81 & 0.86 & 0.29 & 0.64 & 0.86 & 0.9 & - & 0.68 \\
\hline Qinghai & - & 0.66 & 0.89 & 0.75 & 0.74 & - & 0.69 & - \\
\hline
\end{tabular}




\begin{tabular}{ccccccccc}
\hline Tibet & - & - & - & 0.9 & - & 2.86 & 0.84 & - \\
Gansu & 0.74 & 0.58 & 0.9 & 0.81 & 0.77 & 0.77 & 0.74 & 0.51 \\
Max & 1.10 & 1.16 & 1.15 & 1.10 & 1.05 & 2.86 & 1.02 & 0.94 \\
Min & 0.64 & 0.54 & 0.29 & 0.64 & 0.58 & 0.67 & 0.58 & 0.51 \\
Average & 0.91 & 0.79 & 0.80 & 0.82 & 0.81 & 0.90 & 0.76 & 0.70 \\
\hline
\end{tabular}

Notes: The price indices were calculated as $\hat{a}_{c t}=\exp \left(\hat{\alpha}_{c t}\right)$. The base $a_{11}=1$.
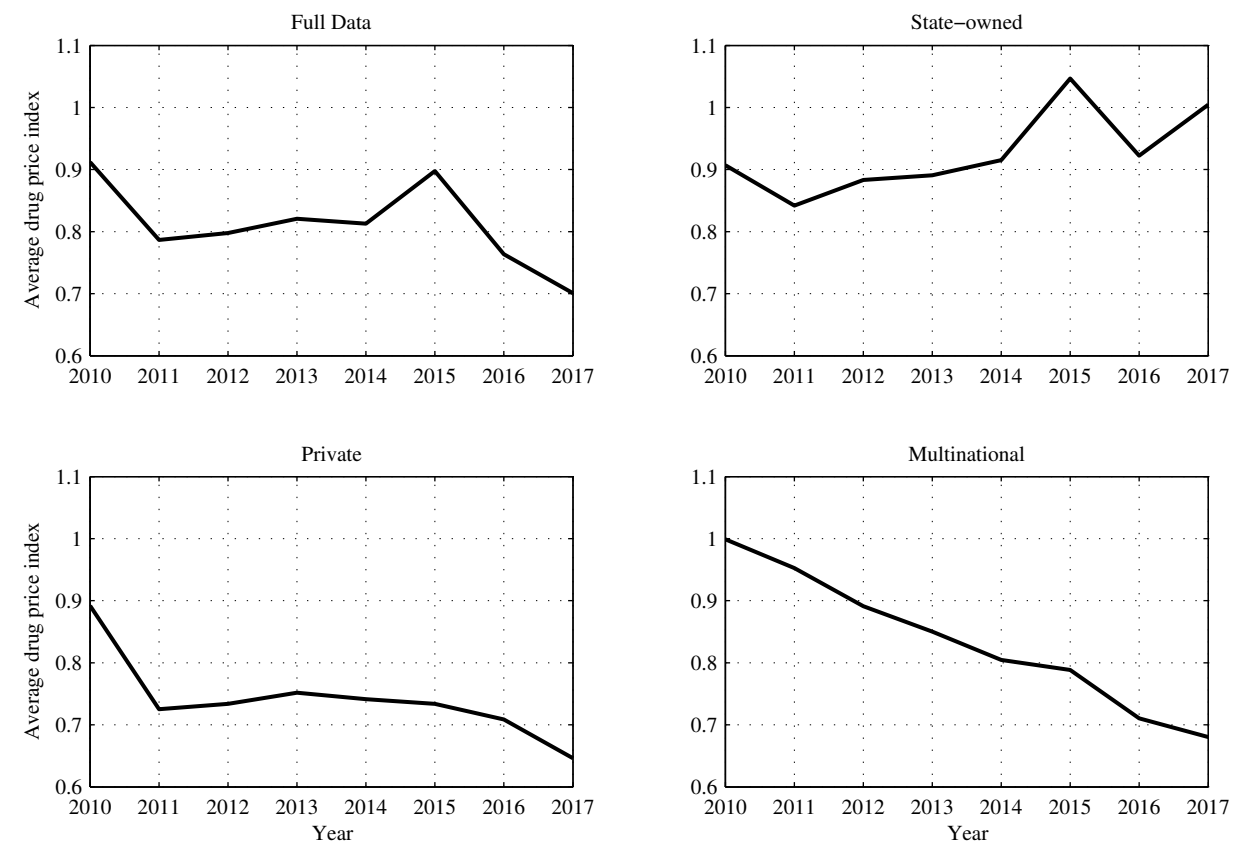

Figure 2. Trends in national price indices for different types of firms. 

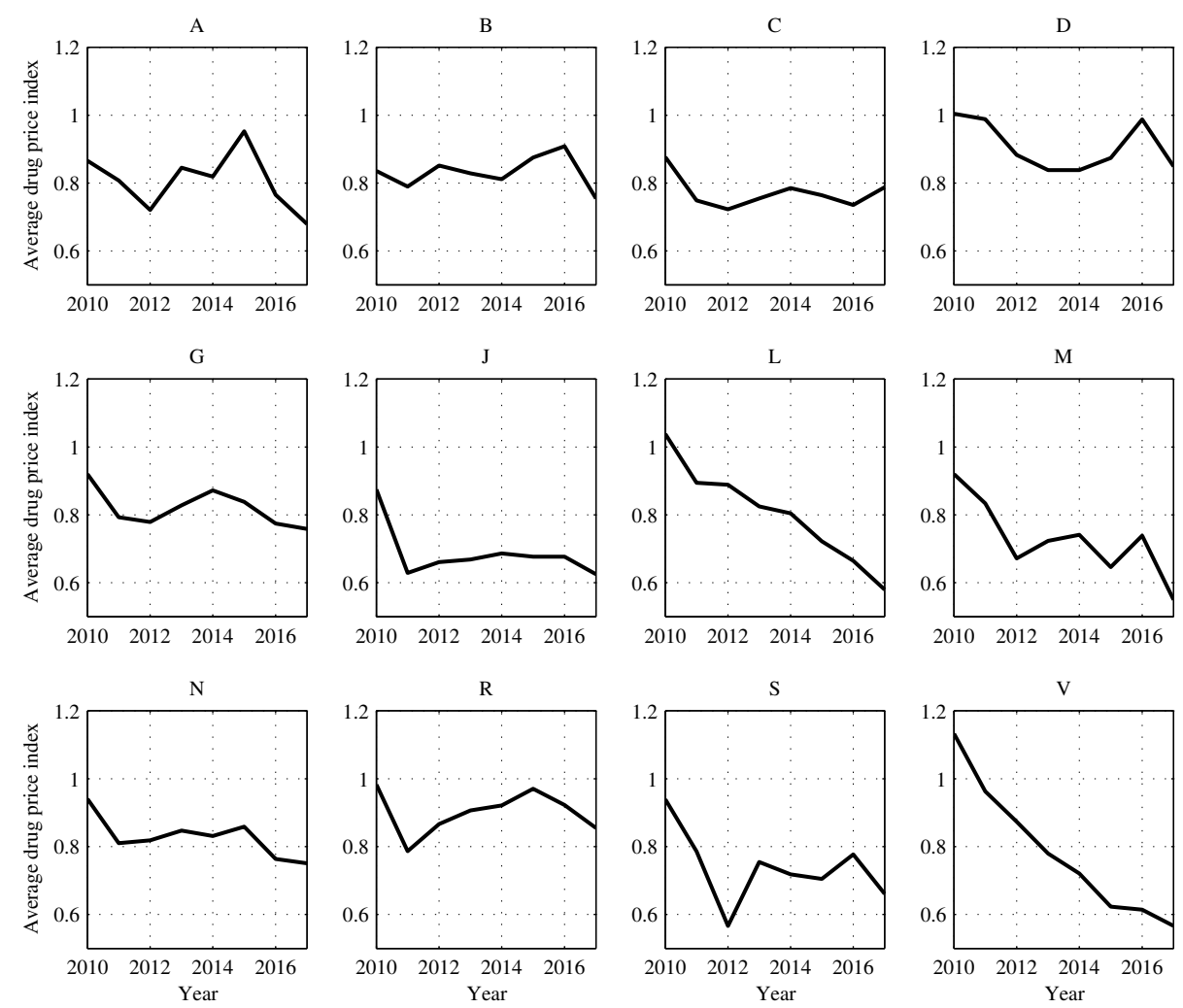

Figure 3. Trends in national price indices for drugs in different anatomical/pharmacological groups.

Abbreviations: A - alimentary tract and metabolism, B - blood and blood forming organs, C - cardiovascular system, D - dermatologicals, G - genito urinary system and sex hormones, H - systemic hormonal preparations, excl. sex hormones and insulins, $\mathrm{J}$ - antiinfectives for systemic use, L - antineoplastic and immunomodulating agents, M - musculo-skeletal system, N - nervous system, P - antiparasitic products, insecticides and repellents, R respiratory system, S - sensory organs, V - various. 

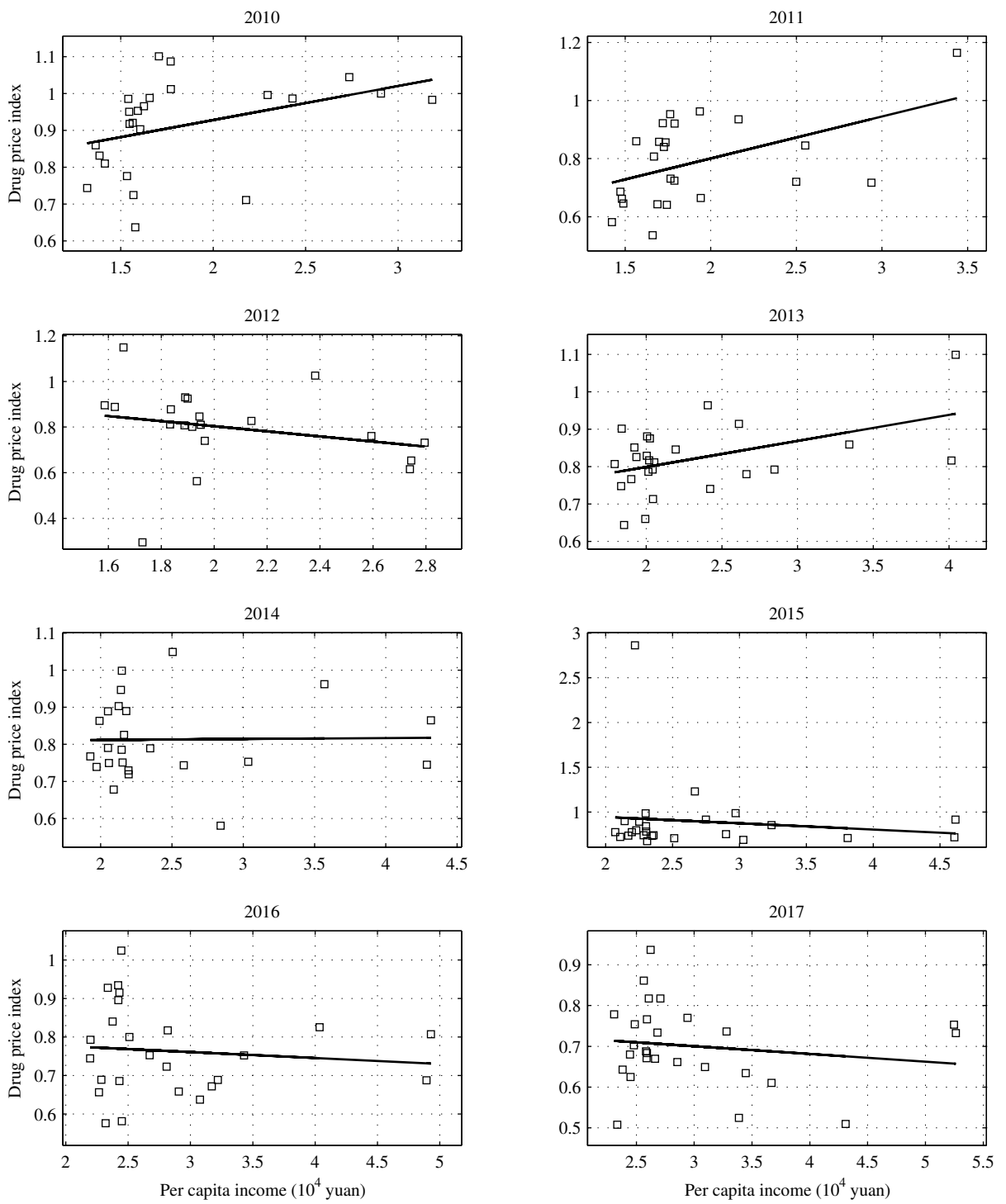

Figure 4. Correlations between drug price indices and provincial income levels from 2010 to 2017 in the full sample.

Notes: Coefficients (P values) of provincial incomes in each year: $0.0926(0.0639)$ in 2010, $0.1445(0.0181)$ in $2011,-0.1119(0.3074)$ in $2012,0.0696(0.0175)$ in $2013,0.0026(0.9402)$ in $2014,-0.0698(0.5779)$ in $2015,-0.0155(0.6279)$ in 2016 , and $-0.0190(0.4531)$ in 2017. 

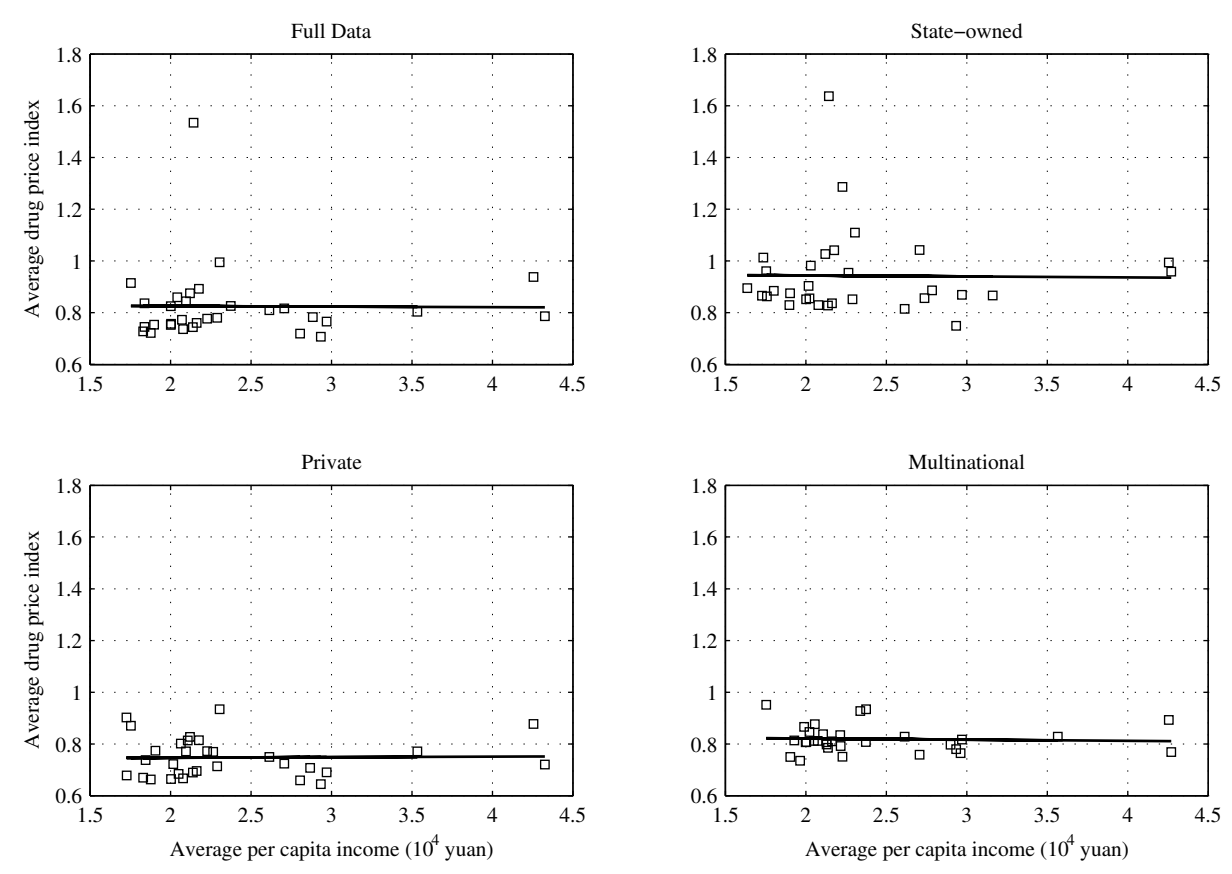

Figure 5. Association between drug price indices and provincial income levels.

Notes: The indices and income levels were calculated as averages over the eight study years.

Coefficients (P values) of provincial incomes for full dataset, Chinese state-owned firms,

Chinese private firms, multinational firms: -1.9e-7 (0.9644), -3.8e-7 (0.9378), 2e-7 (0.9275),

$-4.5 \mathrm{e}-7(0.7739)$. 